\title{
The Influence of Familial and Schooling Experiences on the Acculturation of Immigrant Children from Zimbabwe
}

\author{
Opeyemi Temilola Adebanji
}

Department of Early Childhood Education, University of Pretoria, South Africa

Email: opeyemi.temilola@gmail.com

Nkidi C. Phatudi (PhD)

Department of Early Childhood Education, University of Pretoria, South Africa

Email: nkidi.phatudi@up.ac.za

\section{Cycil G. Hartell (PhD)}

Department of Early Childhood Education, University of Pretoria, South Africa

Email: cycil.hartell@up.ac.za

Doi:10.5901/mjss.2014.v5n20p1039

\begin{abstract}
The challenges confronting neighbouring South African countries such as Zimbabwe continues to increase as a result of the economic down turn it experiences. Consequently people are forced to break barriers in order to cross to South Africa in an attempt to settle down. Their settlement in South Africa presents the reality that their children have to attend South African schools with the attendant challenges and opportunities. Not much is known about how the children of immigrants from Zimbabwe acculturate to the school environment and the South African cultures. Utilising a qualitative case study approach, legitimate peripheral participation, semistructured interviews and observation, this paper explores the impact of familial and school experiences of immigrant children from Zimbabwe on their acculturation to the school environment and the society of sojourn. The study sample consisted of four male immigrant children from Zimbabwe and their parents. The study revealed that familial dynamics seemed to predispose Zimbabwean immigrant children to receive incessant protection in terms of the culture to adopt and the culture to refuse. They were trained at the home front to imbibe their home-based culture and not to inculcate the mainstream culture.
\end{abstract}

Keywords: Acculturation, immigrants, schooling experience, familial capital, cultural influence, Legitimate Peripheral Participation.

\section{Introduction}

Acculturation is a phenomenal and procedural construct, experienced by immigrants in a new society - otherwise referred to as the unusual society. It is a measure of their degree of adaptation to the novel society (Berry 1997; Berry, Phinney, Sam, \& Vedder 2006), in a number of dimensions that are pertinent to their survival and acclimatization. Berry (1980, $1986,1997)$ describes acculturation as a measure of how people negotiate their cultural mores in the midst of contrasting cultural influences. A prominent example is the interaction between immigrant and indigenous children in the same school environment. It is posited that the manner and magnitude to which a person adjusts to the host cultures depends on the individual and the home country (Berry, 1986; Trickett \& Birman, 2005). Immigrant children have been reported to naturally negotiate their position within the host society. They have to deal with multiple challenges including learning a new language, new culture and having to associate with peers who are not ready to assist them in their linguistic confrontations (Von Grünigen, Perren, Nagele \& Alsaker, 2010). Von Grünigen et al. (2010) predisposes the current study to exploring the impact of these dynamics, experienced by immigrant children from Zimbabwe on their coping mechanism at the school and in the mainstream society. It has been observed that the environment in a typical school is not "culturally neutral or value-neutral" (Goddard \& Foster, 2002, p.4) but a reflection of clashes that are revealed in the larger community. The school environment of immigrant children from Zimbabwe becomes a predicament for consideration as a result of the scholarly work of Goddard and Foster (2002). This exploration becomes important because South Africa is referred to as a highly xenophobic community, according to Doodson (2002). 
The route taken by immigrant groups, with respect to the decision to acculturate or not, to the novel society has been indicated to be dependent on their country of origin and certain associated constraints and opportunities they confront. These may range from the degree of belonging to the extent of discrimination experienced by the immigrant children in the new society (Leyendecker \& Lamb, 1999). Many immigrant groups have been reported to choose some kind of biculturalism, where they adjust to the novel culture without giving up their original culture (Portes, 1996; Rumbaut, 1995). According to Portes (1996) a number of immigrant groups are resolved to maintain their cultural identities by being reluctant to negotiate their home cultures with the cultures of the host society. A platform of investigation has been opened to explore the extent of belonging of Zimbabwean immigrant children by exploring their association with the mainstream culture under the tutelage of their parents and teachers. The influence of parents and teachers are viewed as power relations, capable of influencing their decision to adapt to home or scholastic cultures. Since scholastic cultures hinge on the events in the mainstream culture, it would imply that what they learn and practice at school may have a lasting impact on how they choose to behave and adjust to the mainstream culture. Consequently acculturation may be predicted when immigrant children in a novel society indicate their extent of membership of the preferred culture (Berry, 1995; LaFromboise, Coleman \& Gerton, 1993). A number of researchers (such as Berry 1997; Jain \& Belsky, 1997) argue that acculturation entails a dialogic process in which certain perspectives of the immigrant's indigenous and novel cultures intermingle to form a new and unique dimension of conduct, mindset and way of life. Acculturation is also diverse in that the avenues and the degree to which people adjust to the home and host cultures change over time. It differs by the extent to which some characteristics are gathered and certain others are not. It also differs from person to person and from one country to the other (Berry, 1980, 1986; Trickett \& Birman, 2005). It implies that an assortment of experiences negotiated by immigrants in the mainstream society could inform their decision to acculturate or not, as noted by Yeh, Okubo, Ma, Shea, Ou and Pituc (2008). Immigrant children are thus incapable of voluntarily deciding to integrate to a host society. Depending on age and length of stay in the mainstream society, parental influence matters in terms of the ease with which they acculturate to a host society (Piedra \& Engstrom, 2009), as well as the accrued benefits derived by parents from the host society (Adebanji \& Gumbo, 2014).

According to Berry $(1997$, p.9) acculturation occurs in four ways in no particular sequence: (a) integration, in which immigrants uphold their original culture as they gravitate towards the larger culture, (b) assimilation, in which immigrants give up their indigenous culture to take up the culture in the host country, (c) separation, in which the immigrants distinguish themselves from the larger culture and (d) marginalization, in which immigrants demonstrate minimal involvement in both home and foreign cultures. Berry $(1980,1986)$ envisions acculturation as a phenomenon that involves the coming together of two cultures. The propensity of individuals to accept one or reject the other depends on the value they place on their home cultures. It thus implies that the value placed by the parents of immigrant children from Zimbabwe may be used as a yardstick to decipher their extent of affiliation to their preferred cultures. As we reviewed the extant literature, we found that the process of acculturation among immigrants may have complicated and extensive consequences on them. One of these effects is the cultural adjustment to their host country which may be at dissonance with their home culture (Moyerman \& Forman, 1992). Winkelman (1994) announces the impact of cultural adjustment by referring to it as "cultural shock" because of the challenging effect it has on immigrants.

This study becomes imperative in view of the consistent increase in the enrolment of black immigrant children in South African schools. Immigrants from Zimbabwe are reported to constitute the majority among these black immigrants (Tevera \& Zinyama, 2002). An exploration of the consequences of possible cultural attachment or detachment among immigrant children from Zimbabwe in the Foundation Phase becomes paramount in this study. Consequently we sought to answer the following research question in this paper: How do familial and schooling experiences of immigrant children from Zimbabwe affect their acculturation to the school and mainstream society? In an attempt to explore the intellectual puzzles, first, we conduct a review of the literature. Second, the theoretical framework, which provides the opportunity to comprehend how the immigrants from Zimbabwe negotiated their course of acculturation, is discussed. Third, the research approach culminating in the data is presented. Fourth, findings obtained from the collected data are discussed in relation to the findings of other researchers in the literature. Fifth, we draw our conclusion and make recommendation for practice.

\section{Review of Literature}

\subsection{The role of language in acculturation}

A rigorous exploration of the importance of language with respect to acculturation constitutes a particular focus in the research of Yeh et al. (2008, p.784) among Chinese immigrant children who were taken by their parents to the American 
society. They argue:

Acculturation is not only a time to learn new norms and values, and to adopt salient reference groups of the host society, but is a process that includes the ability to grow beyond the original culture and encompass a new culture. Hence, communication is crucial to the adjustment process, and language is the fundamental means of effective communication.

Yeh et al. (2008) present a platform of investigation between the relevance of language and acculturation. It may be perceived that the need to retrieve facts or gain knowledge of the culture of the novel society on a daily basis is hinged around language acquisition. The essence of negotiating the home culture of immigrants with the culture of the novel society seems to constitute a requirement to "grow beyond the original culture" of the immigrant children to incorporate into a novel culture. According to Yeh et al. (2008), language is a means of expressing and negotiating between cultures of host and home countries, resulting in the process of acculturation among immigrant children. The language of instruction at the school is a determinant of academic achievement (Chow, 2006). When immigrant children are unable to learn the language of instruction easily, their academic potential may be hampered. Language proficiency is therefore considered a key player when exploring acculturation among immigrant children. Similarly the ease with which immigrant children learn the indigenous language may also influence their adaptation to the mainstream society. This discussion becomes important because the use of indigenous languages among indigenous South African children during informal conversation may be seen as ubiquitous. On the other hand indigenous children need to be viewed under the lens of being under the relations of power by their parents to uphold the use of the indigenous languages. Immigrant children may have to learn the indigenous languages in order to belong to the group of indigenous children to gain the applause of the indigenous children. If the immigrant children learn the indigenous languages, certain dynamics of power may ensue at both ends of the continuum between the immigrant and indigenous families. Consequently the issues of power dynamics pertaining to linguistic adjustment become a predicament in this paper.

\subsection{Schooling experiences impacting on the acculturation of immigrant children}

Eckhart (2005) worked on factors predisposing children to being rejected and accepted at the school level. The study focused on the mindset and association of Swiss and foreign children. Foreign children were obviously minimally received compared with their Swiss classmates even if their academic performance was commensurate with their indigenous classmates. This mindset towards their immigrant counterparts remained unchanged over the entire period that the study was conducted. The social distance between Swiss and immigrant children was prominent when compared with what existed among indigenous children at the school. It was reported that there was minimal integration between Swiss and immigrant children in terms of interaction and integration at the school. A platform of investigation is thus initiated in this current study to decisively address the degree of interaction between Zimbabwean children in the Foundation Phase and indigenous children at the school level. This presents grounds for analysing the potential of Zimbabwean children to relate and acculturate to their immediate environment. It also opens an avenue of discussion that unveils the connection between their ability to integrate with the social and academic environment as well as the effect this may have on their ability to focus and excel at the school.

Suarez-Orozco and Suarez-Orozco (2001), in their study of children of immigration are of the opinion that the available infrastructure and features at the school may tend to alleviate or aggravate the adaptation of immigrant children to the culture of the new school they find themselves in. This presents the opportunity of exploring the context of the schools in terms of the infrastructure, the attitude of teachers and the friendliness or harshness of the school environment on immigrant children from Zimbabwe in the Foundation Phase. Similarly, Asanova (2005, p.191) posits that "the quality of teacher relationships" with the learners is capable of fostering the acculturation of students to the school environment. These studies informed our decision to explore whether immigrant children from Zimbabwe in the Foundation Phase are at home or not in the schools. This aids our perception to make informed judgment about the available documents and the academic performance of the immigrant children as these reflect their adjustment in the schools. It thus becomes clear that the academic performance of immigrant children may tend to have underlying factors that may continue to predispose them to doing well or refrain from doing well at the school. Consequently we are afforded the opportunity to correlate acculturation and academic performance, because theoretically, when children do not fit into the milieu they find themselves it becomes challenging to adjust to scholastic tenets at the school. 


\subsection{Familial influences on immigrant children's acculturation}

Immigrant parents have been reported to exhibit a great level of involvement regarding the manner in which their children spend their time (Ogbu \& Simons, 1998). Caplan, Choy, and Whitmore, (1992) observe that immigrant families often engage their children in educational activities more than other inconsequential activities which are of little importance to their children's educational endeavours. This may have the propensity to reduce the available time these children have to socialize with their peers. Findings in this direction raise issues regarding how immigrant children interact with peers. It implies, if the level of interaction with peers is diminished, their degree of acculturation may be affected. If the situation is the same with Zimbabwean immigrant parents, we would be able to draw conclusions based on our scope of study on how such restrictions affect the acculturation of immigrant children from Zimbabwe. Kao and Tienda (1995) contend that some vital elements of familial existence, such as disparities in the ways immigrant parents talk to their children about educational experiences and the degree of involvement of parents are capable of affecting academic performance of immigrant children. Such tutelage at the home front may have an impact on how immigrant children relate with peers, if all they do is to move in the direction set by their parents in order to have academic achievements. If such is the case with the immigrant children from Zimbabwe, then we would be able to deduce how familial dynamics impact on the acculturation of Zimbabwean immigrant children in the Foundation Phase. This study therefore aims at exploring the impact of parental involvement on Zimbabwean immigrant children's acculturation. Consequently, it becomes imperative to explore the relational factors existing between Zimbabwean immigrant learners in the Foundation Phase, peers and their parents. It is also of importance to have an understanding of parental expectations of these children with regards to their academic performance and to determine what impact this may have on their acculturation.

\section{Theoretical Background}

The theory of Legitimate Peripheral Participation (LPP) (Lave \& Wenger 1991) was employed in this study. To explicate the understanding of the theory and its relevance to the influence of familial and schooling experiences on the acculturation of immigrant children from Zimbabwe, further discussion is hereby made on the LPP theory.

\subsection{Legitimate Peripheral Participation}

Legitimate peripheral participation (LPP) is perceived as localized learning, because it occurs within a specified locality. Lave and Wenger are of the opinion that learning takes place in different milieus, depending on the offerings of the environment (1991). The specified localities in the context of this study are the primary schools and home environments concerned. Therefore learning is perceived to occur within the confines of a community with the associated prospects and disputes (Lave \& Wenger, 1991). The associated prospects and disputes are power dynamics between the home and school fronts, with certain implications when the acculturation of immigrant children to the school and mainstream society is explored. The concept of LPP presents the opportunity to comprehend the arrival of Zimbabwean immigrant children as legitimate peripheral participants as they are admitted to the school. It also allows an exploration of how they learn via interaction or non-interaction with the other indigenous children, teachers and staff at the school. It assists in evaluating the attendant learning expressed by the Zimbabwean immigrant children as deviant from the conventional forms of academic learning to involve issues relating to how they acculturate and identify with the tenets of the school environment in connection with the acquired values at the home front as well as values they have been able to gain or lose at the school front, drawing on Serpell (2007, p.26). However, the effects of acculturation on academic performance become a key factor in this study, conceptualized as pertinent to the academic identities of the immigrant children from Zimbabwe in the Foundation Phase. We postulate that such academic identities may be due to the communication that these children receive at the home fronts because of hierarchical forces emanating thereof.

Immigrant children from Zimbabwe are perceived as legitimate peripheral participants entering at the periphery of the community (level 1, Figure 1). Lave and Wenger (1991) postulate that the degree of involvement of legitimate peripheral participants in the learning curriculum of the community determines access until full participation is ensured "centripetally" (Wenger, 1998, p.122). We conjecture that when scholastic participation is full, the immigrant learners may be assumed to have acculturated to the school environments. Furthermore, we postulate that since the indigenous learners are representative of the community of children in the mainstream society, adequate communication between the immigrant and indigenous children suggests acculturation to the mainstream society. A pictorial conceptualization of the process is shown in Figure 1 


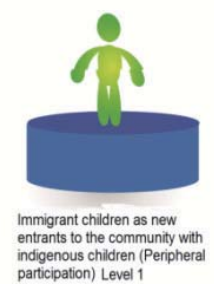

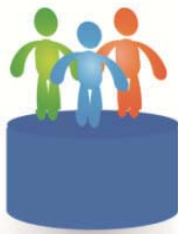

Appreciable participation of immigrant children with indigenous children
Level 2

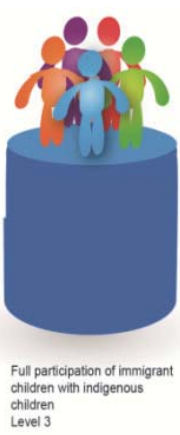

children
Level 3

Figure 1: Pictorial representation of LPP as newcomers enter the community of practice

Newcomers (immigrant children from Zimbabwe) are conceptualized to enter the community at the periphery (level 1 , Figure 1). With the passage of time there is profound interaction between the teachers, immigrant and indigenous children (level 2, Figure 1). At this level the immigrant children attempt to learn the indigenous language of communication and participate considerably in the activities within the community. Consequently they move towards the hub of the community. With deeper penetration into the community via the acquisition of the language of communication (level 3, Figure 1), they begin to learn the culture of the community via participation in the stipulated and non-stipulated activities at their disposal. Stipulated activities could comprise their requirement to focus and learn the curriculum of study at the schools. Non-stipulated activities may be in terms of informal association with their peers who are deemed to be custodians of certain perspectives of the mores and values within the school environment. We draw on Lave and Wenger (1991) that as long as the participation of the newcomers is in a centripetal direction (towards the core of the community) learning will evolve to attain an identity (Lave \& Wenger, 1991). Therefore the school fronts are perceived as battlegrounds where home and school front power relations collide to attain identities which form the philosophies of the immigrant children.

\section{Research Approach}

The case study design was used in this study. In this case study research design, attention was given to specific illustrations of learning experiences with the intention of accessing hypothetical, proficient and deep understanding arising from documented evidence of particular illustrations, drawing on Freebody (2003, p.81). According to Yin (2003) a case study is a practical inquiry designed to explore an existing event, in its natural context, where there is a clear-cut boundary between the event and perspective, with the use of diverse sources of information. Cohen, Manion and Morrison (2007, p.254) propose that case studies could be employed to describe "what it is like" to operate in a particular scenario in order to catch a glimpse of what naturally exists in the real world of research subjects using diverse data sources. A natural context, as it relates to this study, comprises studying immigrant children from Zimbabwe in their natural and familiar environments (their homes and the schools where they attend). This way, a high degree of divergence is not demanded of them "from the place(s) they are used to, what they usually do or who they are usually with" (Mukherji \& Albon, 2010, p.26). Participants were selected from two schools identified to have Zimbabwean immigrant children in the Foundation Phase (purposive sampling). The first parent to indicate interest in participating in the research introduced us to other parents who participated in the study (snowball sampling). Some of the parents earlier contacted refused to participate because a number of them were undocumented immigrants. Hence we took advantage of the parents who indicated their willingness to participate in the study.

\subsection{Research sample}

The research participants constituted four immigrant children from Zimbabwe in the Foundation Phase, and their parents. The children were drawn from two primary schools identified to have Zimbabwean children in the Foundation Phase in a semi-urban area. The children were males and aged between six and seven. The children and their parents were interviewed on one-on-one basis. All the children were born in Zimbabwe before their parents came to South Africa. Their parents had lived in South Africa for more than two years. All the children were living with both parents. 


\section{Data Collection}

Data were collected using observation and interviews. The children were observed in their various homes, to see how they communicated with their parents and at the schools to explore their language of communication with their peers. Interviews were conducted in English with the children and their parents. Verbatim transcription of interviews took place within two days of conducting interviews as no translation was required.

\subsection{Data collection procedure}

Data collection procedure began with obtaining ethical approval from the University Ethics Committee, the Department of Education, the school principals, Schools' Governing Bodies and parents of the immigrant children. Assent of the children was gained by involving their parents who read the letter of assent and explained it to their children. Parents opted to sign the letter of assent on behalf of their children subsequent to their giving consent to participate in the study. The children and their parents were interviewed on one-on-one basis. The interviews were semistructured in nature. Open-ended questions were prepared before going to the field. These served as a guide to direct the course of the interview. The interview protocol for the children consisted of questions in three sections, which are; biographical information, schooling experiences and identity. Questions were asked in ways that were comprehensible and age-appropriate for the children. The questions put to parents centred on their personal experiences since they arrived in South Africa, their children's schooling experiences and their stances toward the South African culture.

The children were observed inside their classrooms and also during playtime on the play field. They were also observed at home. Observation protocol was prepared in advance as an aid to observing various observable aspects of the phenomenon. Observable phenomena such as classroom atmosphere, interaction between learners and teachers, and interaction between immigrant children and the indigenous children were documented in the observation journal. Furthermore interaction of the children with their parents at home was observed. Attention was given to language use and communication. Visits were made to each school two days in a week for three weeks. Visits were made to the home of each learner once.

\section{Data Analysis}

In this study data gathering and analysis proceeded simultaneously. Data obtained from the interviews were recorded and transcribed to categorize key information emerging from the interviews. The real names of the participants have been replaced with pseudo names. Pseudo names given to the children are Tommy, Dave, Chester and Nicholas. The pseudonames given to their parents are Mr. William, Mrs. Tshangarai, M. and Mrs. Chiron and Mr. and Mrs. Timbale respectively.

\section{Findings and Discussion}

In this study discussion is made in terms of the acculturation of the immigrant learners to the academic institution and the mainstream society. This is done as influenced by parents of the immigrant learners. Findings from the study are hereby discussed in relation to the case of each child and his parents. This is because children are legitimate peripheral participants in the home front communities of practice with parents as experts and the children as novices who learn from the ongoing tenets at the home front, drawing on Lave and Wenger (1991).

\subsection{The influence of Tommy's familial and schooling experience on his acculturation experience}

Mr. William was asked if he would mind his son learning the indigenous South African language. He responded by saying "I wouldn't mind him speaking any of the South African languages." This statement was a depiction of Mr. William's liberality with respect to his son's mindset on learning the indigenous South African languages. According to Yeh et al. (2008, p.784), acculturation is not indicative of the learning of new customs and principles, and to embrace "salient reference groups of the host society", but it entails a course that requires the capacity to outgrow the original way of life to imbibe a novel culture. However, Mr. William preferred his son "to grow in his home culture" instead of the South African culture. He reiterated by saying, "I will want him to know his own culture preferably." Cultural preferences are indicative of an identity of choice among immigrant children as suggested by Kohn (2002) and Vandeyar (2008). The notion that Mr. William had that Tommy needed to learn and know his home culture was a deviation from the path of acculturating to the 
mainstream society, although he tolerated his son to learn the indigenous South African language. Mr. William was not oblivious of the route to cultural negotiation. He knew the versatility of language learning as the entry route to definite cultures. Mr. William in his words said, "Culture can be learnt through language." He expressed the route to learning culture by asserting that "At home we speak our home language. Once in a while, at least twice a year, we go back home." The fact that Mr. William and his wife used Shona to communicate with Tommy was an indication that they did not want him to get detached from his cultural roots. This experience seems to support the finding of Wang and Phillion (2007, p.100) that, "the language use of both parents and students at home proves that parents are concerned about their children losing their home language" (Wang \& Phillion 2007, p. 100). The purpose of home visits was geared towards familiarizing Tommy with people of the same cultural origin, a resounding attempt to imbibe home front cultural tenets. Mr. William revealed the mechanism of action to keep Tommy connected to his cultural roots by allowing him to get "exposed to his grandmother and other family" members.

Utilizing the Legitimate Peripheral Participation theory to analyse the scenario (Lave \& Wenger, 1991), we argue that Tommy's association with his peers at the school, in terms of the fact that he was allowed to relate with them, could be taken as legitimate peripheral participation at the time he joined them at the school. The fact that his father was not against him to learn the indigenous South African languages seemed to have given him the currency of negotiating the scholastic and social cultures at the school. His case was enhanced by the capability he had in terms of his proficiency in English which he could use to initiate negotiation of the scholastic culture present therein. Consequently a platform of understanding the indigenous languages was likely made because every unknown indigenous word could be understood via the dimension of interpretation in English. Lave and Wenger (1991) posit that as participants in the community of practice continue to associate with more knowledgeable others via observation of the curriculum of the community, they move inwards centripetally until full participation is achieved (see Figure 1). Mr. William's differentiation, in terms of the extent of acculturation that Tommy could get involved with, could prevent Tommy from moving inwards, centripetally to the full membership status.

The extent of participation between Tommy and his peers could be located within a realm that could only allow him to acquire scholastic acculturation, rather than the acculturation to the mainstream society. Consequently the schooling experiences of Tommy entailed an amiable scenario where his peers in the Foundation Phase related and associated with him to the point that the line of verbal communication was opened for the negotiation of scholastic and academic institution cultures. His father's intervention in terms of limiting his extent of intercultural association was seen as a hindrance to "his becoming" involved in full participation in terms of intercultural negotiation that leads to full membership in the community. Consequently this study agrees with Yeh et al. (2008) that acculturation surpasses the gimmick of learning salient rules and values of the mainstream culture, but involves the capacity of immigrants to outgrow their home culture to incorporate a new one. Familial intervention likely prevented Tommy from outgrowing his home cultures to embrace the mainstream culture. However, the language of learning and teaching was seen as a tool for negotiating scholastic culture.

\subsection{The influence of Dave's familial and schooling experience on his acculturation experience}

Mrs. Tshangarai is Dave's mother. From her account she wanted Dave to acclimatize to the culture of the academic institution. At the same time Dave was not to relinquish negotiation with the Zimbabwean culture. The chosen way to achieve this aim was through the use of Shona language at home, mixed with the use of English. The familial use of English at the home front was targeted at advancing his potential to become versatile at using English at home, which was the tool of instruction at the school. Mrs. Tshangarai's tolerance in terms of the notion that Dave could learn other languages is thus evidenced in her response to our question on language use at the home front. She responded, "Our home language is Shona. We use English just to help them because they attend an English-medium school." This was an indication of his connectedness to the school environment because he could learn the indigenous language at the school. Dave's mother also demonstrated her approval of Dave's freedom to learn all the 11 official languages in South Africa. She said "I'm not worried. He can learn all the 11 languages of South Africa. I am willing to encourage him."

It was clear evidence that his indigenous peers could not hide anything from him because he understood the indigenous language spoken during playtime. As such they saw him as one of them. Dave was versatile at switching from English to Zulu (an indigenous language in South Africa) and back to English. This gave him the leeway into a new cultural domain. The capability that Dave acquired to speak Zulu with his friends during break was an indication of the development of the sense of belonging to the school community. His ability to speak Zulu with his indigenous South African friends was his ticket to becoming accepted so that he could enjoy the social opportunities available at the school front. 
The acculturation experience of Dave was thus seen as a procedural encounter, with the home front flexibility in terms of the tolerance to concurrently learn and speak Zulu and English. This is supported by Chow's (2007, p.512-513) finding that immigrants will procedurally acquire a sense of belonging, making the process of acculturation appear as a procedural and phenomenal construct. Although Chow conducted his study on adolescent immigrants in Canada, it implies that his finding may be extended to immigrant children in the Foundation Phase since they also seemed to negotiate a procedural and phenomenal pathway in terms of how they acculturated.

From the Legitimate Peripheral Participation lens (Lave \& Wenger, 1991), Dave's ability to speak Zulu, Sotho and Sepedi became his currency for negotiating a sense of belonging to the school. His proficiency in these three indigenous South African languages enabled him to transact his acceptance to the community of indigenous children at the school. The indigenous South African children at the school were seen as custodians of the indigenous languages (experts). Dave began to learn these indigenous South African languages as he associated and participated in the discussions with the indigenous South African children who were more knowledgeable than he. Consequently Dave became a full participant as he began to discuss matters with the indigenous South African children in the indigenous South African languages. This study is supported by the theory of Lave and Wenger (1991) that as novices enter a community of practice, they become full participants with centripetal association with more knowledgeable members of the community. It is furthermore posited that as the participation of immigrant children in the community reaches full potential, they are capable of developing the requisite dimension of sense of belonging. The acquired sense of belonging transcends acts of discrimination and prejudice against them by virtue of their capacity to decipher indigenous languages of communication in the community.

By virtue of the connection between acculturation and the negotiation of identities (Yeh et al. (2008), we inquired about Mrs. Tshangarai's stance on Dave's declaration and definition of identity. Mrs. Tshangarai said "I am still thinking about that. I am still in-between. I still want him to be a Zimbabwean but he can make a choice when he is old enough." A thorough analysis of Mrs. Tshangarai's response indicated an uncertain stance regarding Dave's definition of his identity. She was still battling with the possibility that his son could become a South African. This was a clear indication that the definition of identity among immigrants is a struggle that requires both latent and manifest consideration. However, she indicated her choice as Kohn (2002) declares that the issue of identity is a matter of choice within an assortment of experiences that immigrants traverse in the society of sojourn.

Consequently, Mrs. Tshangarai submitted, by virtue of the liberality that she had shown, that it was Dave's prerogative to decide whatever he wanted for himself. This was a clear indication that as immigrant children acculturate to a novel multicultural domain, they do so with considerations in line with parental judgment and liberality until they become old enough to choose whether to belong to the novel society or to relinquish belonging to that novel society. Going by Kohn's (2002) suggestion that the issue of identity requires a consideration of choice and a range of experiences in the society of sojourn, this study affirms that the development of a sense of belonging among immigrant children is not a stereotypic scenario, but involves familial predisposition and the child's futuristic dimension of experiences. Dave seemed to be taking too much of the indigenous South African cultures via the acquisition of the indigenous languages that he could speak. This finding supports the work of Tong, Huang and McIntyre (2006) that when immigrant children are too attached to other cultures within an environment, they may need to forgo their culture and ethnic identity if they take up too much of the majority culture.

\subsection{The influence of Chester's familial and schooling experience on his acculturation experience}

Chester was an amiable boy. He was seven years old. He was proficient in his home language (Shona) but could not converse in English or any of the indigenous South African languages. An intellectual puzzle emerges as to how he managed to interact with his indigenous peers at the school because language of communication aids the process of acculturation as suggested by Yeh et al. (2008). However Chester's father (Mr. Chiron) was a linguistically liberal person. He did not mind his son learning the indigenous languages. On Mr. Chiron's stance on learning languages, he said: "I do encourage my children to learn different languages because language is power." However his linguistic tolerance was in terms of mobility. Mr. Chiron saw the learning of the indigenous languages in the light of its capability to aid the mobility of his son. He said: "It's like education. When you learn something, it's to your advantage. It's a tool for communication. You can move anywhere and you can communicate." Mr. Chiron saw language as a ladder that assists in climbing and negotiating cultures. His narrative gives us an understanding of the ploy of immigrant parents who are linguistically liberal. They seem to be linguistically malleable because of the future goal of having their children in multiple dimensions of places and cultures in order to make them eligible for versatility to fit into diverse perspectives of cultures. By virtue of the seamless relationship between language and acculturation as suggested by the scholarly work of Yeh et al. (2008), we 
became interested in exploring Mr. Chiron's state of mind about his son learning the South African culture. He said Chester could learn the South African culture but that he had to ensure he would not practise it. As far as Mr. Chiron was concerned, learning a culture is different from putting it into practice. This suggests that parents of immigrant children mind their children practising another culture that is different from their home culture. This, we believe, could mean that he only wanted his son to learn the South African culture to be able to interact with the indigenous children and integrate into the system. However, a quick presentation of Mr. Chiron's argument brings out an important issue as far as acculturation to the mainstream society is concerned. Socializing with members of the mainstream society is thus seen in this study as an approval of Mr. Chiron's acceptance of his son's acculturation to the mainstream society for the purpose of acquiring the capacity to adjust to the academic terrain of the school environment. He revealed his stance on the issue of culture by saying:

\begin{abstract}
I have to understand exactly from which point he wants to take it from. Learning is not a problem. It's a little bit to his advantage. If he wants to learn there is no problem but he must not practice it. Learning and practicing are two different things. I don't have any problem with learning. He can understand more about the people around him.
\end{abstract}

It has been suggested in literature that acculturation and identity mediation are complex processes which are intricately connected and negotiated (Adebanji, 2010; Yeh et al., 2008). When Mr. Chiron was asked how he wanted his son to be referred to, in terms of identity, he responded "I would want my son to be referred to as a Zimbabwean." Mr. Chiron was definitive in terms of his liberality to allow Chester to learn the indigenous South African cultures. This was an indication that Mr. Chiron minded his son getting being fully adjusted in the South African society. His liberality in terms of his son learning the South African culture was vested towards academic motive. This kind of familial predisposition of acculturation seemed to have been aimed at Chester's understanding of his academic environment so that he could focus on his studies. It was not targeted at his mainstream acculturation experience that could lead to eventual settlement.

\title{
7.4 The influence of Nicholas' familial and schooling experience on his acculturation experience
}

Nicholas was the youngest of the children participants. His parents, Mr. and Mrs. Timbale had an objective that was in line with Nicholas' academic potential. They wanted Nicholas to be proficient in English because it was used to teach at Bakwena Primary School. They were made up in their minds that as long as he stayed in South Africa, he would be capable of speaking the indigenous South African languages even if they discouraged him. However it was their choice that he had to learn English at all costs. This was due to their futuristic goal of wanting to prepare him for international opportunities.

Mr. and Mrs. Timbale were of the mindset that Nicholas did not need to speak any of the South African languages. They seemed to be drawn away that speaking an indigenous language is a measure of withdrawal from home front cultural tenets. However there was no intervention on their part to impede his move to learn the indigenous languages. This family was seen as a sensitive family in terms of their cultural predisposition. They held more tenaciously to home front cultural tenets than the other parents that were interviewed in this study. This finding gave us the information that different families tend to hold on to home front cultural tenets than the others. Nicholas' parents opined:

He speaks the local languages but we don't encourage him. When he is at home he pretends like he doesn't know how to speak. But we know he speaks. I don't know which one of the languages he speaks in particular because it's a mixture.

Nicholas' parents expressed their feelings in terms of the versatility of English as an international language. They wanted him to develop his ability to speak fluently in English because of the future prospects it could bring. We obtained first-hand information on how Nicholas' vocabulary was built. He had a furnished predisposition to learning and speaking English from the home front. This home front approval of English as a language of communication assisted him to adjust to the curriculum. The learning of the local languages assisted him to acculturate to the academic environment. This was an indication that familial expectations in terms of the future prospects of immigrant children could provide a foundation that may propel the children towards achieving academic excellence. Mr. and Mrs. Timbale spoke further:

The thing is that even our own Shona language he will easily pick up. We know that as long as he remains here he will pick the South African language. We want him to master English. We want to mould him to be internationally prepared so that wherever he goes he would be able to speak internationally. If you go to most countries English is the medium of communication. 
Mr. and Mrs. Timbale were of the opinion that teaching their son the Zimbabwean cultural tenets was important. They were determined to do this by teaching him the Zimbabwean language which was to lead him to the details on his home country culture. They reiterated:

We teach him things that are related to our culture which we want him to do. By that he would be learning our culture gradually. At this age we cannot teach him everything that he needs to know about our culture. But we gradually teach him some good values that will form part of his culture. Already he has his own subculture, a mix of South African culture and our Zimbabwean culture.

Mr. and Mrs. Timbale however made a stern disapproval of Nicholas totally imbibing the culture of South Africa. They apparently felt objected to this. They said: "We would actually mind if he totally takes on the South African culture. That's why we are always close to him."

Their concern about Nicholas' proficiency in the indigenous language was an indication that he could become integrated into the mainstream society beyond their control to the point that he could relinquish his Zimbabwean cultural orientation. It is posited in this study that certain immigrant children negotiate selective acculturative processes by virtue of their parent's involvement in the course of their lives in the unusual society. The experience of Nicholas and his parents in terms of not permitting him to learn the languages of South Africa was an indication that immigrant children are predisposed to growing "up with strong ties to two countries, two cultures, and two ways of being, which can produce multiple realities, multiple ways of being and communicating with the world" (Rodriguez, 2009, p. 17).

These experiences seem to support the argument of Rodriguez (2009, p.17) because Nicholas' parents attuned him to growing up with two different cultures but emphasized a measure of preponderance towards the Zimbabwean cultures while he was at the same time encouraged to learn the LoLT.

Utilizing the legitimate peripheral participation theory (Lave \& Wenger, 1991), we argue that Nicholas' participation on the periphery of the school was not devoid of familial input. He seemed to have carried the home cultural tenets to the school as he journeyed through the school to associate and participate in the school curriculum. His participation within the school with his indigenous South African peers was likely with the idea that he could not learn the indigenous South African languages. However he confronted the reality that he could only speak English with his friends. We perceive in this study that the assertion by his parents that he did not have to speak in the indigenous language was a rule that had scope at the home front. This was because Nicholas spoke the indigenous languages in his private space away from the familial influence. Our argument becomes vital at this point because despite the command given to him that he should not speak the indigenous South African languages, he spoke them fluently. Consequently his acculturation negotiation trajectory could become a mixture of academic acculturation and an avoidance of the mainstream acculturation which was constantly being checked by his home front dynamics and control to stay away from learning the indigenous South African cultural tenets.

Employing the scholastic lens provided by Vidali and Adams (2007), it becomes understandable that Nicholas' parents seemed to have made his acculturation to the mainstream society complex. This was because he was being tailored by home cultural injunctions whereby his communication with the indigenous South African cultural mores was being shifted away from his perception and consideration. Nicholas' ability to decode the mainstream cultural principles was blurred by the home front cultural adherence as stipulated by his parents. The observable reason for this complication was due to the fact that he was a child and as such had to go along with the dictates of his parents as to which culture to choose and embrace. A challenging aspect of his acculturation which Mr. and Mrs. Timbale could not influence was in the dimension of learning the indigenous South African languages which he involuntarily picked up via his association with more knowledgeable others, drawing on Reyes' (2007) scholarship. We bring the argument of Lave and Wenger (1991) to this discourse at this instance by arguing that his (Nicholas) association with peers who spoke the indigenous languages seemed to have inclined him to understanding and speaking a number of these indigenous languages involuntarily.

\section{Conclusion}

Berry $(1997,1980,1986)$ proposes that acculturation ensues in four ways, and it progresses in no specific order: (a) integration, in which immigrants maintain their usual culture as they settle into the mainstream culture, (b) assimilation, in which immigrants relinquish their home culture to adopt the culture in the unusual society, (c) separation, in which the immigrants differentiate themselves from the mainstream culture and (d) marginalisation, which is disconnection from both home and foreign cultures. This appears to summarize the acculturative tendencies explored so far among the 
Zimbabwean immigrant learners in the Foundation Phase especially from their familial and schooling experiences. From the available evidence drawn from the research respondents of this study we summarise the acculturation predicaments of immigrant children from Zimbabwe as follows:

- Familial dynamics seemed to predispose these Zimbabwean immigrant children to receive incessant protection in terms of the culture to adopt and the culture to refuse. Parents of these Zimbabwean immigrant learners were firm in terms of how their children could become integrated to the South African society en route to their exposure to unfamiliar cultural principles at their disposal. These immigrant parents, however, maintained unanimous stances towards the development of their children's academic identity. This seemed to limit the children to Berry's $(1997,1980,1986)$ acculturation stage of integration. These children were able to uphold their home culture as they moved towards the majority culture of the host society.

- None of the Zimbabwean immigrant learners in the Foundation Phase experienced acculturative stress in the mainstream South African society. At the school they enjoyed an amiable association with their indigenous South African peers. The fact that Chester did not speak nor proficiently comprehend English did not deter him from associating with his friends. This was an indication that among immigrant learners in the Foundation Phase, language may not be a barrier to associating and relating with their indigenous peers. According to Madhavappallil and Choi (2006), immigrant adolescent children in the United States of America were found to experience acculturative stress. It could be argued that their (adolescent) age was likely responsible for their outright choice that directed them in the direction of opposing their home front cultural principles handed over to them by their parents. In this context the immigrant learners from Zimbabwe were still very young, and were not predisposed to taking the dimension of reasoning and independence undertaken by the adolescent immigrant children that were explored in the United States of America by Madhavappallil and Choi (2006). We argue that acculturative stress may not normally be experienced by immigrant learners in the Foundation Phase because children find their ways of interacting together, even when they are temporarily hampered by language barrier. Furthermore, we argue that home front tutelage as to how they are to interact with predominant culture may not be held in high esteem at the school front because of their freedom to play with indigenous peers.

\section{Recommendation}

Immigrant parents should be educated on allowing their children to learn the indigenous languages of the host country to enhance integration of their children into the novel culture. This is because language difficulty can incite fear and anxiety in children. This may be a hindrance to expected results, especially within the classroom (Gonzalez-Ramos \& SanchezNester, 2001). Parents should realise that allowing their children to learn the indigenous language does not necessarily mean that the children will relinquish the home language. Parents should however engage their children by speaking their home language so that their immigrant children can keep the home front language while at the same time learn the language of learning and teaching as well as the other languages spoken that can enhance their adjustment profile to the mainstream society. Furthermore it is supposed that when immigrant children acquire the necessary dimension of acculturation to the school environment through the comprehension of a language of communication, they tend to focus on academic learning. Familial interventions may seem to complicate the acculturative stance of immigrant children to the extent that they are limited and incapacitated to take on the culture of the adopted society.

\section{References}

Adebanji, C.A. (2010). The educational and sociocultural challenges of immigrant students in a South African Schools. Unpublished M.Ed. Thesis. University of Pretoria.

Adebanji, C.A. \& Gumbo, M.T. (2014). Curriculum experiences militating against the education of immigrant students in a public South African school. Mediterranean journal of social sciences, 5(1), 387-397.

Asanova, J. (2005). Educational experiences of immigrant students from the Former Soviet Union: A case study of an ethnic school in Toronto. Educational Studies, 31(2), 181-195.

Berry, J.W. (1980). Acculturation as varieties of adaptation. In A.M. Padilla (Ed.) Acculturation: Theory, models and some new findings (pp. 9-25). Boulder, CO: Westview Press.

Berry, J.W. (1986). The acculturation process and refugee behavior. In C.L. Williams \& J. Westermeyer (Eds.). Refugee mental health in resettlement countries (pp. 25-37). Washington, D.C: Hemisphere.

Berry, J.W. (1997). Immigration, acculturation, and adaptation. Applied Psychology: An International Review, 46(1), 5-34.

Berry, J.W., Phinney, J.S., Sam, D.L. \& Vedder, P. (2006). Immigrant Youth: Acculturation, Identity, and Adaptation. Applied Psychology: An International Review, 55(3), 303-332. 
Caplan, N., Choy, M.H. \& Whitmore, J.K. (1992). Children of the Boat People: A study of Educational Success. Ann Arbor: The University of Michigan Press.

Chow, H.P.H. (2006). Vietnamese-Canadian university students in Regina: Socio-cultural and educational adaptation. Canadian Ethnic Studies, 38(2), 104-112.

Chow, H.P.H. (2007). Sense of belonging and life satisfaction among Hong Kong adolescent Immigrants in Canada. Journal of Ethnic \& Migration Studies, 33(3), 511-520.

Cohen, L., Manion, L. \& Morrison, K. (2007). Research methods in education $6^{\text {th }}$ ed.). London: Routledge.

Doodson, B. (2002). "Gender and the brain drain". SAMP Migration Policy Series No. 23. Cape Town: SAMP.

Eckhart, M. (2005). Anerkennung und Abtehnung in Schulklassen: Einstellungen und Beziehungen von Schweizer Kindern und Immigrantenkindern [Recognition and rejection in schools: Attitudes and relationships of Swiss children and immigrant children]. Bern: Haupt Verlag.

Freebody, P. (2003). Qualitative research in education: Interaction and practice. London. SAGE.

Goddard, J. T. \& Foster, R. Y. (2002). Adapting to Diversity: Where Cultures Collide-Educational Issues in Northern Alberta. Canadian Journal of Education, 27(1), 1-20.

Gonzalez-Ramos, G., \& Sanchez-Nester, M. (2001). Responding to immigrant children's mental health needs in the schools: Project mi tierra/my country. Children and Schools, 23(1), 49-63.

Jain, A. \& Belsky, J. (1997). Fathering and acculturation; Immigrant Indian families with young children. Journal of Marriage and the Family, 59, 873-883.

Kao, G. \& Tienda, M. (1995). Optimism \& achievement: The educational performance of immigrant youth. Social Science Quarterly. Population Research Center, University of Chicago.

Kohn, T. (2002). Becoming an Islander through Action in the Scottish Hebrides. Journal of Royal Anthropological Institute (N.S.) 8, $143-158$.

LaFromboise, T., Coleman, H.K. \& Gerton, J. (1993). Psychological impact of biculturalism: Evidence and theory. Psychological Bulletin, $114,395-412$

Lave, J. \& Wenger, E. (1991). Situated learning: Legitimate peripheral participation. Cambridge: Cambridge University Press.

Leyendecker, B. \& Lamb, (1999). Latino families. In M. Lamb (Ed.). Parenting and child development in nontraditional families. Mahwah, New Jersey: Lawrence Erlbaum Associates.

Madhavappallil, T. \& Choi, J.B. (2006). Acculturative stress and social support among Korean and Indian immigrant adolescents in the United States. Journal of Sociology and Social Welfare, 33(2), 123-143.

Moyerman, D.R. \& Forman, B.D. (1992). Acculturation and adjustment: a meta-analytic study. Hispanic Journal of Behavioural Sciences, $14,163-200$.

Mukherji, P. \& Albon, D. (2010). Research methods in early childhood: An introductory guide. Londen: SAGE.

Ogbu, J.U. \& Simons, H. (1998). Voluntary and involuntary minorities: A cultural-ecological theory of school performances with some implications for education. Anthropology \& Education Quarterly, 29(2), 155-188.

Portes, A. (1996). What shall I call myself? Hispanic identity formation in the second generation. Ethnic and Racial Studies, $19,523-547$.

Reyes, R. (2007). A collective pursuit of learning the possibility to be: The CAMP experience assisting situationally marginalized Mexican American students to a successful student identity. Journal of Advanced Academics, 18(4), 614-659.

Rodriguez, T. (2009). Schooling and language learning in a transnational context. The High School Journal, 16-33.

Rumbaut, R. (1995). The new Californians: Comparative research findings on the educational progress of immigrant children. In R. Rumbaut \& W.A. Cornelius (Eds.), California's immigrant children: Theory, research, and implications for educational policy (pp. 17-69). San Diego:

Serpell, R. (2007). Bridging between orthodox western higher educational practices and an African sociocultural context. Comparative Education, 43(1), 23-51.

Suarez-Orozco, C. \& Suarez, Orozco, M.M. (2001). Children of immigration. Cambridge: Harvard University Press.

Tevera, D. \& Zinyama, L. (2002). Zimbabweans who move: Perspective on international migration in Zimbabwe. The Southern Africa Migration Project, Migration Policy Series 25.

Tong, V.M., Huang, C.W. \& Mclntyre, T. (2006). Promoting a positive cross-cultural identity: reaching immigrant students. Reclaiming Children and Youth, 14(4), 203-208.

Trickett, E.J. \& Birman, D. (2005). Acculturation, school context, and school outcomes: Adaptation of refugee adolescents from the former Soviet Union. Psychology in the Schools, 42(1), 27-38.

Vandeyar, S. (2008). Changing Student-Teachers' Beliefs and Attitudes in South African Classroom. In E. Weber (Ed.). 2008. Educational change in South Africa: Reflections on local realities, practices and reforms. Sense Publishers.

Vidali, E.L. \& Adams, L.D. (2007). A challenge of transnational migration: Young children start school. In L.D. Adams \& A. Kirova (Eds.). Global migration and education. London: Lawrence Erlbaum Publishers.

Von Grünigen, R., Perren, S., Nagele, C. \& Alsaker, F.D. (2010). Immigrant children's peer acceptance and victimization in kindergarten: The role of local language competence. British Journal of Developmental Psychology , 28, 679-697.

Wang, Y. \& Phillion, J. (2007). Chinese American students fight for their rights. Educational Foundations, 21(1-2), 91-105.

Wenger, E. (1998). Communities of practice: Cambridge, England. Cambridge University Press.

Winkelman, M. (1994). Cultural shock and adaptation. Journal of counselling and development, 73, 121-126.

Yeh, C.J., Okubo, Y., Ma, P.W., Shea, M., Ou, D. \& Pituc, S.T. (2008). Chinese immigrant high school students' cultural interactions, acculturation, family obligations, language use, and social support. Adolescence, 43, 172, 775-790.

Yin, R.K., (2003). Case study research: Design and methods. (3rd ed.). Thousand Oaks, CA: Sage. 